\title{
Evaluation of Alternative Approaches in Designing Bioscience Curriculum for a Heterogeneous Student Audience
}

\author{
Humaira Qureshi \\ Department of Integrated Sciences and \\ Mathematics, \\ Dhanani School of Science and \\ Engineering, \\ Habib University, Pakistan
}

\author{
Javeria Samad \\ Department of Integrated Sciences and \\ Mathematics, \\ Dhanani School of Science and \\ Engineering, \\ Habib University, Pakistan
}

\begin{abstract}
Habib University provides world class liberal arts and sciences education in Pakistan where students are not only provided with an in-depth knowledge of their field of study but are also exposed to a breadth of other subjects. This equips the student to develop a holistic approach to problems and is imperative in solving the fast evolving challenges that the world faces today. In order to fulfil the natural science elective requirements, students who are non-biology majors take courses in biosciences. These students have a diverse background with respect to previous knowledge about biology, ranging from almost none to advanced level. There is also a wide disparity based on majors as students come from different programs in arts as well as sciences. Engaging such a heterogeneous population in bioscience electives requires out of the box approaches. Some of the strategies that have proven effective are discussed in this article. An interdisciplinary approach for project-based learning and group activities were rated highest amongst the students. The article also highlights useful modifications for the future to further improve the quality of the curriculum.
\end{abstract}

\section{Introduction}

Habib University is the very first liberal arts institute in Pakistan, showing equal representation of sciences and arts. It has two schools, Dhanani School of science and engineering (DSSE) and School of Arts, Humanities and Social Sciences (AHSS). DSSE offers two majors; Computer Science (CS) and Electrical Engineering (EE) while two majors, Social Development and Policy (SDP) and Communication and Design (CND) are offered under AHSS.

Habib University follows seven forms of thoughts namely Historical and Social Thought, Philosophical Thought, Language and Expression, Formal
Reasoning, Quantitative Reasoning, Natural Scientific Method and Analysis, and Creative Practice [1]. All courses fall under one of these categories and all students have to fulfil certain requirements from each category.

In particular, a natural science elective requirement is mandatory in higher educational and liberal arts institutions. Natural science courses at Habib University are a combination of pure sciences (Biology, Physics and Chemistry) with some interdisciplinary aspects to cater to the needs of all the majors being offered at the Habib University.

Two courses of biosciences, "Cell biology and Public Health" and "The Secret World of Microbes" were offered as electives to fulfil this natural science requirement. All data presented here is representative of the two courses.

\section{Challenges}

Since Habib University is a liberal arts university and the bioscience elective courses were offered to a diverse group of students (all of whom were nonbiology majors) it was quite challenging to make the course equally interesting and engaging for all the students as well as to meet the subject requirements. The possible levels of biology education prior to entering undergraduate school in Pakistan is as follows:

1. $8^{\text {th }}$ Grade Biology

2. O level/Matric Biology (equivalent to High School Sophomore)

3. A level/F.Sc. Biology (equivalent to High School Senior)

Based on this prior level of biology education, the student audience in our class was a heterogeneous population, with $27 \%$ having a background in $8^{\text {th }}$ grade or lower level biology (Figure 1). While the other aspect that made our population divergent was due to variations in major disciplines (Figure 2). 


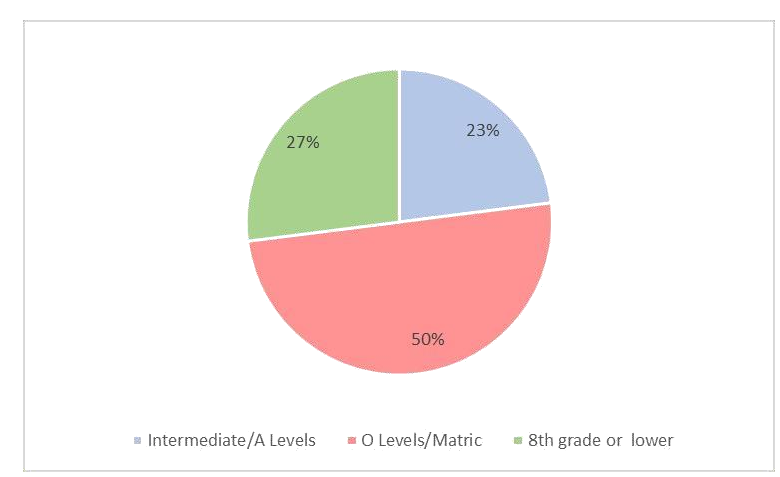

Figure 1: Heterogeneity based on prior level of biology education $(n=56)$

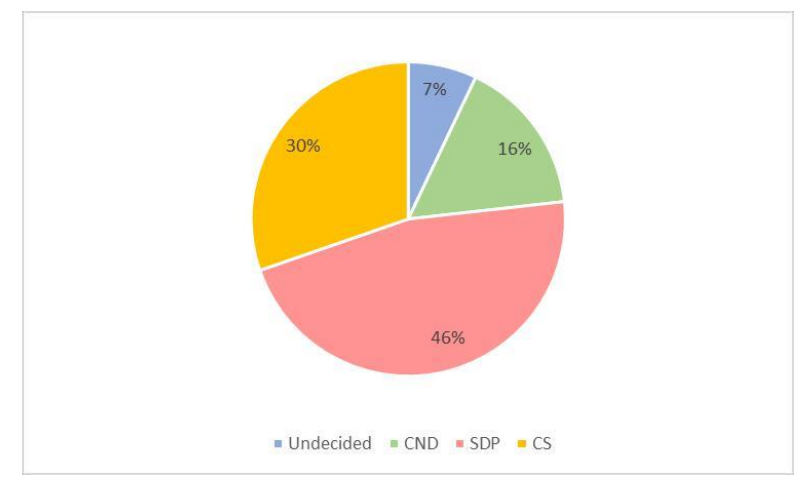

Figure 2: Heterogeneity based on major discipline $(n=56)$

\section{Interdisciplinary Approach}

Considering the diversity of students, both in terms of their majors and prior level of biology education, the courses integrated an interdisciplinary approach so as to keep the interest of the students alive.

In the public health section of the course, we targeted the diseases which are endemic in our society and discussed the biology behind these diseases. It helped the students when they went to the community level for their project and contacted the stakeholders of that specific disease. They were well aware of the risks associated with the disease and were able to communicate preventive measures to the people more effectively. This public health aspect of biology course was more helpful for students of social development and policy.

The course activities and projects also had the design element to effectively utilize the students creative and art skills, based on their aptitudes and interest. Students used photography and designing techniques in their assignments and were awarded grades for that part as well. This aspect was most interesting and satisfying for communication and design students.

Students also got to learn about the basics of bioinformatics and used different databases available for DNA sequence analysis. This aspect catered to the curiosity of the computer science students

Overall, the interdisciplinary approach aided in engaging the students from all the majors to a certain extent as it was in keeping with their aptitudes.

\section{Strategic approaches}

\subsection{Active learning}

Since the class comprised of a heterogeneous audience a number of active learning approaches had to be employed in order to keep the students well engaged. Group and individual class activities, worksheets, short videos, illustrative cartoons and posters and object-based learning were part of the class sessions.

Benefits: It keeps the students more involved and interested and helps create a better understanding of the subject.

Limitations: It takes some more time than a normal lecture and some students may get overwhelmed with these class activities and worksheets.

\subsection{Seating arrangement}

Students were seated in groups of four with pairs of two facing each other. It allowed students to work together easily and shifted away from lecturebased learning

Benefits: It promotes peer learning and makes the group-based activities more interactive.

Limitations: All the students cannot face the teacher at the same time in case he/she starts explaining on the board, so they have to move their seats in between the class. Sometimes students start talking or get involved in loud discussions which creates a disturbance for others.

\subsection{Use of Clickers}

It is a variation of Just-In-Time Teaching (JiTT) [2]. A web-based tool, Socrative, was used to assess the student understanding at the individual level [3]. It allows the student to respond to questions individually and anonymously, using their smartphones or laptops.

Benefits: It ensures complete class participation as you can check the number of responses on the screen. It allows the students to answer without the fear of exhibiting their mistakes, as it does not show the names. It also helps the teacher to gauge the overall understanding level of the whole class after a topic is explained or during class to expose misunderstandings.

Limitations: Sometimes students keep using their phones and devices after the activity is over and get distracted from the class. Sometimes students 
come up with silly answers on purpose because they know the answer will appear anonymously and they will not get caught.

\subsection{DNA puzzle kit}

A commercially available DNA puzzle kit was used for hands on activity so students could develop a better understanding of the DNA structure and its basic components [4]. Using these puzzle pieces, students were able to construct a single nucleotide, join multiple nucleotides to form a long single strand of DNA (or RNA), as well as the double strand of DNA with the specific complementary orientation. They understood the double and triple bonds between the complementary pairing of the nitrogenous bases and the sugar phosphate backbone structure and how it supports the DNA. Students liked this activity because it made the DNA structural details and specifications, easier and clear to them.

Benefits: This hands on practice greatly helps the students to grasp the concept all the while making the DNA structure more fun to study. It provides a good visual memory for the students to remember the DNA structure.

Limitations: Some students begin to fix the pieces of the puzzle together without comprehension and the teacher has to make sure their understanding is complete before moving on. Some of the students got overwhelmed with the chemical structures and bonds shown in the puzzle pieces so they just tried to fix the pieces together rather than focusing on the specific bonds.

\subsection{Videos and animations}

Different animations and descriptive videos were shown to students in order to clarify the structural and functional features of cellular mechanisms, cell organelles, DNA replication, protein synthesis, microbial growth, infections and immune system, and diseases mechanisms. These videos were well illustrated and the visual effects facilitated in concept building [5, 6].

Benefits: The simple videos help the students to develop a better understanding of the subject in an easier manner especially for the students with limited prior information in biology.

Limitations: Sometimes students do not pay attention in the class while watching the video because they believe they can watch it later on their own.

\subsection{Use of simulation lab kits}

Commercially available kits for Mitosis and Meiosis (from Fisher Scientific) were used to demonstrate the basic concepts of cell division. Students were able to create illustrative phases of cell division, showing chromosomal structures using coloured pop beads, provided in the kit. It helped the students to better understand the structure and function of chromosomal aberration, crossing over and genetic recombination [7].

Benefits: It allows the students to clearly differentiate between two types of cell division, with an enjoyable experience. Concepts for diploid and haploid cells are clarified and reinforced.

Limitations: Students need to be kept in check that they are focused on the task. They sometimes get carried away with the beads and centromere when creating the chromosomes and hence start building a bead 'necklace'!

\subsection{Cell Models}

Students had to construct a 3D model of the cell, as part of their assignment, clearly showing the cell organelles, using any material. In another assignment students were asked to create models of unicellular organisms like viruses, bacteria or yeast using everyday material. Students got to exhibit their creative skills with different innovative ideas for the model making. They used different materials to create the model like coconut shell (used to show the cell body) and components with playdough and plaster of Paris), edible jelly (different colored jelly to show different organelles), edible cake with colored icing to represent cell components, cantaloupe to make the cell body with playdough based components and also a unique wooden model using their knowledge gained from the engineering workshop at the university (Figure 3).

Benefits: As the students make the model themselves, it serves as an effective method for them to remember the cell structure and each organelle in detail.

Limitations: Some students find it a bit tedious so they do not take much interest and create the cell structure poorly. In some groups not all the members participate equally so other members get overburdened.

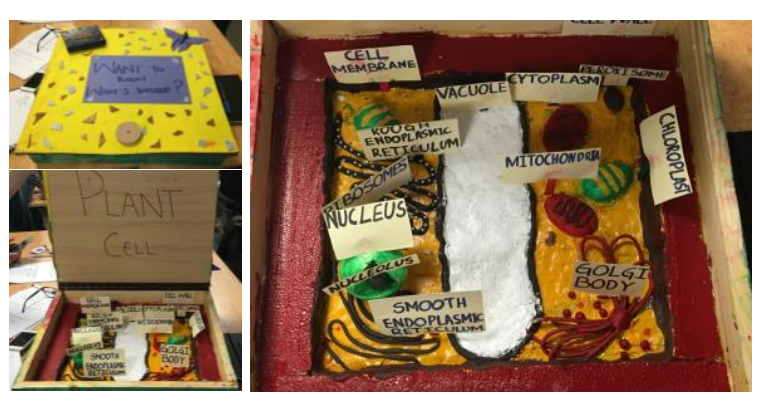

Figure 3: Plant cell model created with wood at engineering workshop 


\subsection{Group projects}

Group work is essential to learning in a heterogeneous class. Apart from group assignments students were asked to work on a final project and this final project held the most weightage in terms of assessment. Project work was done in groups of 3 or 4 students. Project progress was assessed and monitored by assigning the timeline for different tasks. like literature search, sample collection, lab testing, data analysis, report submission and presentation. Other soft skills included teamwork, writing and presentation skills, interpersonal skills, management and organizational skills, field work and community service element. The tasks and skill set to be learned and assessed are mentioned in Figure 4.

One of the public health related project was based on diseases, from malfunction at cellular level to its impact on the body as a whole, at the personal level of the individual and finally at the larger community level. Students had to choose and work with any stake holder of that particular disease and at the end come up with any new strategy (presented as an artifact) to deal with that disease and come up with a unique and effective way to spread awareness about it in the general public. Students were encouraged to use any of their specific skill set for the project like their communication and design skills, programming or web developing skills, language, engineering and technical skills. They came up with very creative strategies including blood screening campaign at the campus, radio adds, pamphlets, web pages and apps.

In the project assignment for the microbes course, students had to do microbial screening for different food items, places and objects and check the antibiotic resistance for those specifically identified microbes. It involved the sample collection from field, lab testing for identification (culturing and biochemical testing), results and data analysis and poster presentations.

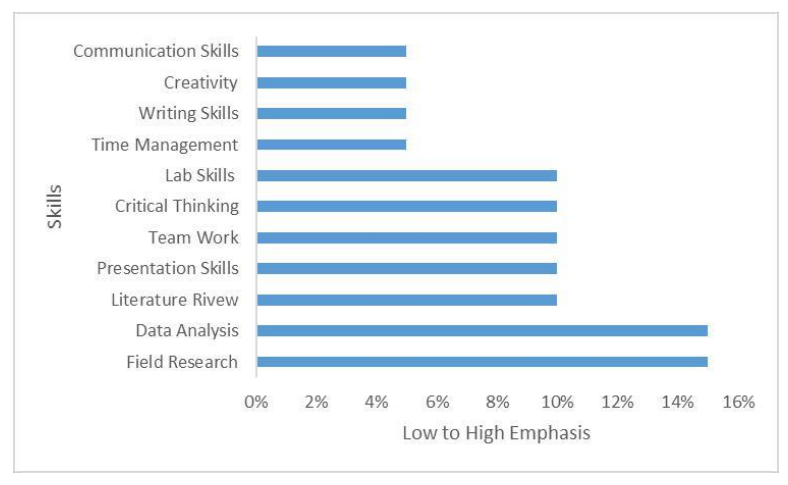

Figure 4: Project goals according to learning emphasis
Benefits: Project work improved multiple skill sets of students and compelled them to study/search in detail about the topic leading to better understanding of the problem.

Limitations: Even though marks are allotted for student contribution by the group members, not all the group members contribute equally in the project thereby overburdening others.

\subsection{Field study}

Field study was part of students' assignments and group projects. They either had to collect samples for lab testing from the field or conduct a survey in the community to collect data and propose some strategy to resolve the existing problem. In some cases, they had to contact any stakeholder related to that particular project. Taking consent from the participants was also part of their field study.

Benefits: It gives the students' community exposure and they learn how to deal with public health related issues. It improves their selfconfidence and interpersonal skills.

Limitations: Community research requires more time. Not all participants prove to be cooperative.

\subsection{Invited Speakers}

For some of the important and interesting topics, experts from industry or renowned research institutes were invited as a guest speaker. It was an interactive session in which they delivered lectures and conducted hands on sessions as well.

Benefits: Students got to interact with the relevant field experts and learnt from their experiences. A hands-on session on bioinformatics was more fascinating for the students.

Limitations: It requires more time to arrange such sessions. Few students did not feel comfortable enough to ask queries from the guest speaker.

\subsection{Special lab sessions}

Based on most of the theoretical topics, lab sessions were specially arranged to clarify concepts and to give a hands-on experience to the students. They got the opportunity to extract DNA from peas, strawberries and bacterial culture suspensions. They also tested their ABO blood group. Microbial identification techniques including bacterial culturing (streaking, swabbing and suspension culture), bacterial identification (biochemical testing \& Gram staining), bacterial enumeration (CFU counting), and antibiotic susceptibility testing (Kirby Bauer method) were performed by the students. This allowed them the skills to do the final lab based project at the end.

Benefits: Students found the lab sessions interesting and helpful in concept building and it 
gave them some technical hands on skills too. It made the students familiar with the bio lab environment and the biosafety rules like the use of PPEs, cleaning and sterilization, preventing themselves and the environment from spreading microbes.

Limitations: Since the courses were not assigned as lab-based courses we had to utilize class time for this activity.

\subsection{Assessment techniques}

Modified methods of assessment were employed to gauge the students' learning. Peer grading was an essential component of group assignments to balance the grades in case one group member failed to put in his share of the work. Some quizzes were in the form of IF-AT (Immediate Feedback Assessment Technique) pattern so peer learning could be promoted [8]. Since a lot of the time was spent on class activities there were specific marks for class participation to ensure that students partake in activities and give a meaningful contribution. Final project had the most weightage, as it demanded a lot of time and field study. Exams in the form of open books gave the advantage to the students so they did not have to remember the difficult terms in biology.

\section{Summary for strategic approaches}

Students appeared to appreciate the unconventional methods we employed. The students found the learning experience through the projects as the most beneficial (Figure 5). As part of the public health approach, students got to directly interact with the local society and improve their communication and interpersonal skills. The artefacts designed by the students to create public awareness served as a unique form of community service.

The content taught not only helped the students to create awareness but also to be vigilant about their self-health needs such as getting vaccinations on time and donating blood in a safe manner.

A lot of the students expressed the desire to enrol in a subsequent course in bioscience as shown in Figure 6.

\section{Future Modifications}

\subsection{Proper lab sessions}

One modification that we felt can be included is having proper three-hour lab sessions as opposed to shorter sessions that were held during class time to demonstrate few important concepts. It was observed that students enjoy lab sessions more as it gets them out of the classroom and more involved in the subject. Students will also have time to learn advanced lab skills as opposed to fewer, shortcut methods.

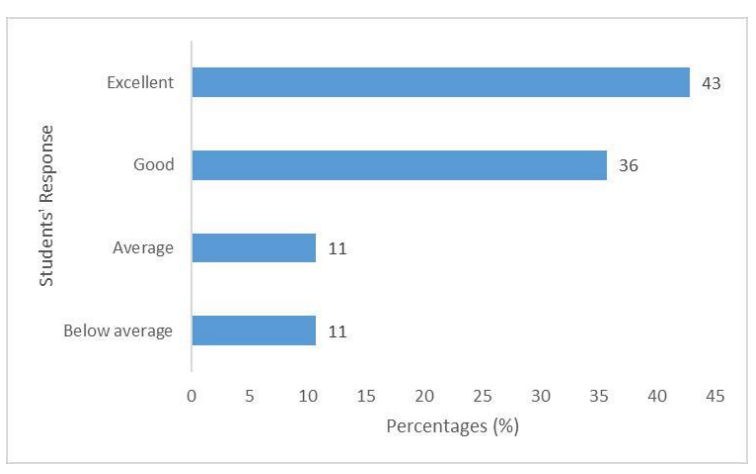

Figure 5: Learning experience via interdisciplinary projects

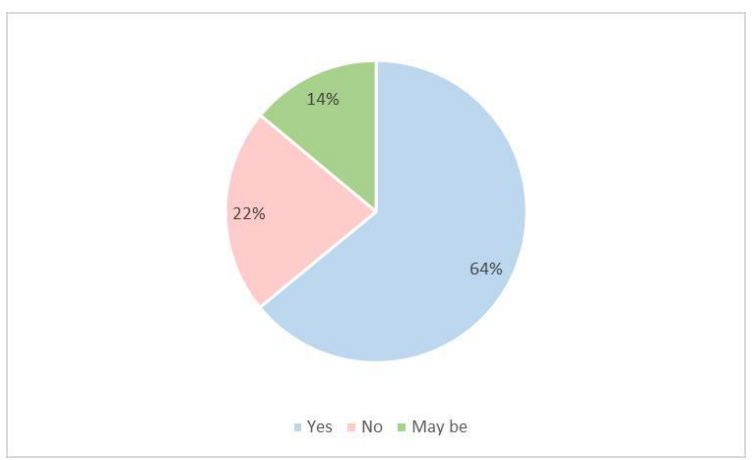

Figure 6: Students interested in studying more biology courses

\subsection{Final Project instead of exams}

Removing midterm and final exams and adding their weightage to the final project is another alteration to the course that can be made. Exams require more memorization whereas project-based learning has more benefits.

\subsection{Project work allotment}

Early allotment of project work will ensure that students have a better grasp over their work and can start planning ahead. A lot of students had issues with their team members as well which would allow them more time to switch members in case they felt incompatible.

\subsection{Budget for printing posters}

The courses did not include any funding for posters that had to be printed as part of the final project. This resulted in unsatisfaction from the students upon having to pay a considerable amount out of pocket for large coloured poster prints. Hence, allotting a budget from the school for this activity in advance will resolve this issue. 


\subsection{Personas for group work}

Having balanced group members in terms of student skills is essential for a group's performance. We plan to use Personas to categorize students according to similar traits. Students will choose a persona that they identify with the most so there will be equal representation and peer learning will be enhanced as students will complement each other's skills [9].

\subsection{Graded worksheets for the lab}

An important alteration is to make sure that all lab worksheets are graded in order to compel students to finish them and turn them in on time.

\section{Conclusion}

Even though there are many advantages to the alternative approaches mentioned here not all alternative approaches work best for every course. It is up to the instructor to find the right balance and as discussed under future modifications there is always room for tweaking to improve the quality of the education and enhance the learning experience.

\section{References}

[1] Habib forms of thought, https://habib.edu.pk/ academics/habib-core/seven-forms-of-thought/ (Access date: 8 October 2018).

[2] Just in Time Teaching, https://cft.vanderbilt. edu/guides-sub-pages/just-in-time-teaching-jitt/ (Access date: 8 October 2018).

[3] Socrative, https://www.socrative.com/ (Access date: 8 October 2018).

[4] Original DNA puzzle kit, Carolina Biological Supply company https://www.carolina.com/genetic-dnamodels/original-dna-puzzle-kit/171050D.pr?

question=DNA+puzzle+kit\# (Access date: 8 October 2018).

[5] Microbiology, $6^{\text {th }}$ Edition, http://highered. mheducation.com/sites/0072556781/s_tudent_view0/ index.html (Access date: 8 October 2018).

[6] 'Science! With the Amoeba Sisters TM", http://www.amoebasisters.com/, (Access date: 8 October 2018).

[7]"Mitosis and Meiosis Lab Investigations", Fisher Scientific; https://www.fishersci.com/

shop/products/mitosis-meiosis-lab-investigations-3/p-

2369235\#tab1 (Access date: 8 October 2018)

[8]"What is the IF-AT?", Epstein Educational enterprises; http://www.epsteineducation.com/ home/about/_(Access date: 8 October 2018).
[9] Adapted from Student Centered Learning Workshop at Olin College. Developing and Using Personas, http://www.olin.edu/about/Presidents-council/Recent -meetings/october-2017/. (Access date: 8 October 2018). 